SHORT COMMUNICATION

\title{
Zamioculcas zamiifolia novel plants with dwarf features and variegated leaves induced by colchicine
}

\author{
K.A.C.N. Seneviratne ${ }^{1, *}$, K.A.J.M. Kuruppu Arachchi ${ }^{2}$, G. Seneviratne ${ }^{3}$ and M. Premarathna ${ }^{3}$ \\ ${ }^{1}$ Department of National Botanical Gardens, Peradeniya, Sri Lanka. \\ ${ }^{2}$ Department of Botany, The Open University of Sri Lanka, Nawala, Nugegoda, Sri Lanka. \\ ${ }^{3}$ National Institute of Fundamental Studies, Hantana Road, Kandy, Sri Lanka.
}

Received: 11/09/2019; Accepted: 01/04/2020

\begin{abstract}
Zamioculcas zamiifolia (Lodd.) Engl. is an exportoriented, potted foliage plant used for indoor scaping. Since it shows high environmental and pest tolerability, it does not need much attention in cultivation. Thus, the aim of present study was to develop stable, novel mutants of $Z$. zamiifolia induced by colchicine (a mutagenic chemical) treatment. Three leaflet types (rooted leaflets with tuber, tuber initiating leaflets without roots and freshly harvested leaflets) were applied separately with four concentrations of colchicine ranging from 0 to $0.4 \%$ to induce mutations in a $70 \%$ shaded greenhouse The experiment was conducted for three generations. Results showed that at $0.4 \%$ and $0.04 \%$ colchicine, plant size decreased in some leaflets, thus producing extreme dwarf and semi dwarf plants, respectively, which are suitable to be used as table-top, miniature ornamental plants. Some leaflets at $0.004 \%$ colchicine produced yellow and light green variegated leaflets. According to our knowledge, this is the first report of producing $Z$. zamiifolia plants with variegated leaves using colchicine. Other than molecular breeding, which is costly and takes a longer period, conventional breeding cannot be employed to generate new plants, since there is only one species under this genus. As such, use of chemical mutagens such as colchicine would provide a rapid means of developing new plant types of this species with attractive morphological features since there is a very narrow range of variants available in the world.
\end{abstract}

Keywords: Zamioculcas zamiifolia, Chemical mutagens, Colchicine, Miniature ornamental plants.

\section{INTRODUCTION}

A wide range of tropical plant varieties are exported as rooted cuttings, un-rooted cuttings, cut foliage, live plants, flower seeds, cut flowers and canes (a semifinished plant material). The assortment includes both local and imported varieties. There is an interest in producing novel cultivars with characteristics such as attractive leaf shapes, colours, sizes and plant architectures (Seneviratne and Wijesundara, 2004; Datta and Teixeira da Silva, 2006; De, 2017). For this, genetic engineering is still a comparatively costly technique, providing a valuable means of expanding the floriculture gene pool for promoting generations of novel marketable varieties.
Out of cost-effective techniques, mutation breeding is an established method for crop improvement and has played a prominent role in the development of new varieties (Seneviratne and Wijesundara, 2004; Datta et al., 2005; Ibrahim et al., 2018), within a short time period (Jambhulkar, 2002; Datta et al., 2005). Colchicine (a chemical mutagen) treatmenthas been recognized as a simple and rapid method for mutation breeding, which induces polyploidization in a shorter period by interfering with mitosis of cells (Eng and Ho, 2019; Fatima et al., 2015; Azmi et al., 2016). Resulted plants from colchicine treatment show features like compact growth habit and broader, thicker leaves (Liu et al., 2007), and also increased leaf length and width, and increased petiole, flower and pollen diameters (Zhang et al., 2016).

Z. zamiifolia is a potted foliage plant used for indoor scaping. There is only one species with a specific set of features in the genus Zamioculcas. Of this species, leaf color improvement and pattern generation would further increase consumer demand. The easiest and most rapid method to do it is the use of chemical mutagens. Z. zamiifolia has a very high export demand (Tarran et al., 2007; Wong, 2009). Since it shows high environmental and pest tolerability, it does not need much attention in cultivation. As an advantage for an indoor plant, $Z$. zamiifolia contributes to purify indoor air very effectively (Guieysse et al., 2008; Sriprapat and Thiravetyan, 2013; Sriprapat et al., 2014; Tarran et al., 2007). There is only one species with a specific set of features in the genus Zamioculcas (Burchett et al., 2008; Wong, 2009). Of this species, improvement of plant architecture, leaf color and pattern generation would further increase consumer demand. Therefore, a study has been carried out with colchicine treatment to induce mutants in Z. zamiifolia to achieve leaf development for floriculture industry

\section{MATERIALS AND METHODS}

The experiment was conducted for three generations $\left(\mathrm{m}_{1} \mathrm{v}_{1}, \mathrm{~m}_{1} \mathrm{v}_{2}\right.$ and $\left.\mathrm{m}_{1} \mathrm{v}_{3}\right)$ over a period of 24 months in a greenhouse at the Royal Botanic Gardens, Peradeniya, Sri Lanka from May 2017 to May 2019. Z. zamiifolia can 
be propagated vegetatively using leaflets with petiole bases (Seneviratne et al., 2013; Irga et al., 2016; Thongkham and Phavaphutanon, 2018). Three types of basal leaflets were selected for this study; 60 day-old rooted leaflets with tuber, 14 day-old tuber initiating leaflets without roots, and freshly harvested leaflets leaving ca. $0.5 \mathrm{~cm}$ of petiole. They were wrapped with cotton wool and dipped in different concentrations of colchicine solutions (50 $\mathrm{ml}$ each; 0, 0.004, 0.04 and 0.4\%) (Seneviratne et al., 2013). Treated samples were removed at two different time periods (24 and $48 \mathrm{~h}$; Seneviratne et al., 2013) from the solutions. Then, they were washed thoroughly with distilled water and transplanted into $11 \mathrm{~cm}$ diameter plastic pots containing 1:1 (v/v) sand and coir dust and placed under a $70 \%$ shaded greenhouse. After one month once rhizomes start to appear, they were transplanted individually into 2 inch pots containing a moistened mixture of river sand, coir dust and compost $(1: 1: 1, \mathrm{v} / \mathrm{v} / \mathrm{v})$. This represented the first generation $\left(\mathrm{m}_{1} \mathrm{v}_{1}\right)$.

Morphological characters were observed for a period of six months. Plants with attractive foliar variations and plant architecture (extreme dwarf, dwarf and variegated leaflet) were selected for planting in subsequent generations. Thus, after six months from planting, the attractive plants were replanted in 2 inch pots containing above potting mediumin a $70 \%$ shaded greenhouse for $\mathrm{m}_{1} \mathrm{v}_{2}$ and $\mathrm{m}_{1} \mathrm{v}_{3}$.

The colchicine treatments were applied as mentioned above to all leaflet types, and they were arranged in a Completely Randomized Design (CRD) with 65 replicates for each type of leaflet in $\mathrm{m}_{1} \mathrm{v}_{1}$. Number of plants produced per leaflet (sprout number), total root length, plant fresh weight, plant height, chlorophyll content and leaflet number per plant were recorded. Data were statistically analyzed using GLM procedure and means were separated with Tukey's HSD test (SAS, 1999).

\section{RESULTS AND DISCUSSION}

Total numbers of plants of $\mathrm{m}_{1} \mathrm{v}_{1}, \mathrm{~m}_{1} \mathrm{v}_{2}$ and $\mathrm{m}_{1} \mathrm{v}_{3}$ were 195 , 26 and 26, respectively. Colchicine treated plants exhibited different responses, depending on concentration used (Table 1).

Colchicine treatments over 24 h (i.e. 48 h) led to death of all leaflets showing symptoms of toxicity (Manzoor, 2016). At 0.4\% colchicine, plant height and fresh weight decreased significantly $(\mathrm{P}<0.05)$ in the rooted leaflets as well as leaflets with tuber (ca. $20 \%$ out of 65 leaflets), thus producing extreme dwarf plants (height reductions compared to the control were $76 \%$ and $95 \%$ of rooted leaflets and leaflets with tuber, respectively), which are suitable to be used as table-top, miniature ornamental plants (Fig. 1a).

Breuer et al. (2007) also reported a similar observation with Arabidopsis where extreme dwarf mutants were resulted upon colchicine treatment. Further, the leaflet with tuber at $0.04 \%$ colchicine produced semi dwarf plants (ca. 12\% out of 65 leaflets) with small, succulent leaves (Fig. 1b). Their height reduction compared to the control was $28 \%$. This observation is in agreement with the report by Seneviratne and Wijesundara (2004), who succeeded in producing such dwarf plants of African violet treated with $0.05 \%$ colchicine for $18 \mathrm{~h}$. Stunting and death of growing points occurred in two cultivars of zinnia (Zinnia violacea) with colchicine application ( $\mathrm{Gu}, 2015)$. Colchicine-induced dwarfing in auto tetraploid is reported to be regulated by hormones like indole acetic acid and brassinosteroid (Ma et al., 2016). In the present study, even the lowest concentration of $0.004 \%$ colchicine significantly reduced root length of rooted leaflets, and tuber circumference of both the rooted leaflets and the freshly harvested leaflets $(\mathrm{P}<0.05)$. The reduced plant parameters could be due to lowered internal auxin concentration with colchicine application, which leads to decreased sizes of plant parts (Aisyah and Marwoto, 2001; Seneviratne and Wijesundara, 2004). Generally, colchicine treatment of plant parts having emerging roots is more effective than those having dry and mature tissues, because large numbers of tetraploid plants are produced by penetrating colchicine through soft tissues (Lehrer et al., 2008; Pirkoohi et al., 2011). This can explain variations of response of different leaflet types to colchicine in our study. Total leaf number and sprout number did not change significantly with the colchicine application.

The highest colchicine concentration of $0.4 \%$ significantly lowered chlorophyll content of the rooted leaflets $(\mathrm{P}<0.05$, Table 1$)$. In agreement with this study, colchicine treatment produced albino plants with significantly low chlorophyll content in pineapple (Mujib, 2005). In our study, the leaflet with callus at $0.004 \%$ colchicine produced yellow and light green variegated leaflets (ca. 2\% out of 65 leaflets) (Fig.1c). It has been reported that polyploidy beyond tetraploid produces variability in colour intensities and shapes of coloration in leaves (Jadrná et al., 2011), possibly due to disintegration of thylakoid membrane system in polyploid plants (Xu et al., 2010). All the plant variants in the present study were stable for the three generations tested.

According to our knowledge, this is the first report of producing plants with variegated leaves of $Z$. zamiifolia using colchicine. Other than molecular breeding, which is costly and takes a longer period, conventional breeding cannot be employed to generate new plants, since there is only one species of this genus. As such, developing new plant types of this species using colchicine etc. should be employed rapidly since there is a very narrow range of variants available in the world. 
Table 1: Plant parameters of $Z$. zamiifolia when different leaflet types were treated with different concentrations of colchicine for 24 hours in the first generation $\left(\mathrm{m}_{1} \mathrm{v}_{1}\right)$.

\begin{tabular}{|c|c|c|c|}
\hline \multirow{2}{*}{$\begin{array}{c}\text { Colchicine } \\
\text { concentration }(\%)\end{array}$} & \multicolumn{3}{|c|}{ Leaflet type } \\
\hline & $\begin{array}{c}\text { Rooted } \\
\text { leaflet } \\
\text { with } \\
\text { tuber }\end{array}$ & $\begin{array}{c}\text { Leaflet } \\
\text { with tuber }\end{array}$ & $\begin{array}{c}\text { Freshly } \\
\text { harvested } \\
\text { leaflet }\end{array}$ \\
\hline \multicolumn{4}{|l|}{ Plant height $(\mathrm{cm})$} \\
\hline 0.4 & $2.9 \mathrm{~cd}$ & $0.6 \mathrm{~d}$ & $11.9 \mathrm{a}$ \\
\hline 0.04 & $9.7 \mathrm{ab}$ & $9.6 \mathrm{ab}$ & $8.7 \mathrm{ab}$ \\
\hline 0.004 & $11.7 \mathrm{a}$ & $6.2 \mathrm{bc}$ & $1.4 \mathrm{~d}$ \\
\hline 0 (distilled water) & $12.2 \mathrm{a}$ & $13.3 \mathrm{a}$ & $12.4 \mathrm{a}$ \\
\hline \multicolumn{4}{|l|}{$\operatorname{MSD}(0.05)=4.76$} \\
\hline \multicolumn{4}{|l|}{$\mathrm{CV}(\%)=26.0$} \\
\hline \multicolumn{4}{|l|}{ Total root length $(\mathrm{cm})$} \\
\hline 0.4 & $15.3 b$ & $26.1 b$ & $27.4 \mathrm{~b}$ \\
\hline 0.04 & $20.8 b$ & $25.2 b$ & $26.0 \mathrm{~b}$ \\
\hline 0.004 & $19.9 \mathrm{~b}$ & $21.5 b$ & $19.3 b$ \\
\hline 0 (distilled water) & $59.4 \mathrm{a}$ & $25.9 b$ & $60.7 \mathrm{~b}$ \\
\hline \multicolumn{4}{|l|}{$\operatorname{MSD}(0.05)=15.40$} \\
\hline \multicolumn{4}{|l|}{$\mathrm{CV}(\%)=24.2$} \\
\hline \multicolumn{4}{|c|}{ Tuber circumference $(\mathrm{cm})$} \\
\hline 0.4 & $7.2 b$ & $7.0 \mathrm{~b}$ & $6.6 b$ \\
\hline 0.04 & $9.2 \mathrm{~b}$ & $8.8 \mathrm{~b}$ & $8.9 \mathrm{~b}$ \\
\hline 0.004 & $7.5 \mathrm{~b}$ & $9.5 b$ & $8.6 \mathrm{~b}$ \\
\hline 0 (distilled water) & $14.0 \mathrm{a}$ & $6.5 b$ & $13.1 \mathrm{a}$ \\
\hline \multicolumn{4}{|l|}{$\operatorname{MSD}(0.05)=3.13$} \\
\hline \multicolumn{4}{|l|}{$\mathrm{CV}(\%)=16.1$} \\
\hline \multicolumn{4}{|l|}{ Plant fresh weight (g) } \\
\hline 0.4 & $3.9 \mathrm{~b}$ & $4.0 \mathrm{~b}$ & $11.6 \mathrm{a}$ \\
\hline 0.04 & $13.2 \mathrm{a}$ & $10.1 \mathrm{ab}$ & $9.6 \mathrm{ab}$ \\
\hline 0.004 & $9.9 \mathrm{ab}$ & $10.6 \mathrm{a}$ & $11.5 \mathrm{a}$ \\
\hline 0 (distilled water) & $13.7 \mathrm{a}$ & $12.4 \mathrm{a}$ & $13.8 \mathrm{a}$ \\
\hline \multicolumn{4}{|l|}{$\operatorname{MSD}(0.05)=6.39$} \\
\hline \multicolumn{4}{|l|}{$\mathrm{CV}(\%)=28.3$} \\
\hline \multicolumn{4}{|c|}{ Chlorophyll content (spad) } \\
\hline 0.4 & $30.3 \mathrm{bc}$ & no leaves & $48.8 \mathrm{a}$ \\
\hline 0.04 & $42.5 \mathrm{ab}$ & $40.4 \mathrm{abc}$ & $36.0 \mathrm{abc}$ \\
\hline 0.004 & $38.9 \mathrm{abc}$ & $29.5 \mathrm{bc}$ & $25.2 \mathrm{c}$ \\
\hline 0 (distilled water) & $47.7 \mathrm{a}$ & $49.1 \mathrm{a}$ & $49.1 \mathrm{a}$ \\
\hline \multicolumn{4}{|l|}{$\operatorname{MSD}(0.05)=16.39$} \\
\hline $\mathrm{CV}(\%)=19.1$ & & & \\
\hline
\end{tabular}

Values in the same column followed by the same letter are not significantly different at 5\% probability level, according to Tukey's HSD test. $\mathrm{MSD}=$ minimum significant difference. $\mathrm{CV}=$ coefficient of variation. 


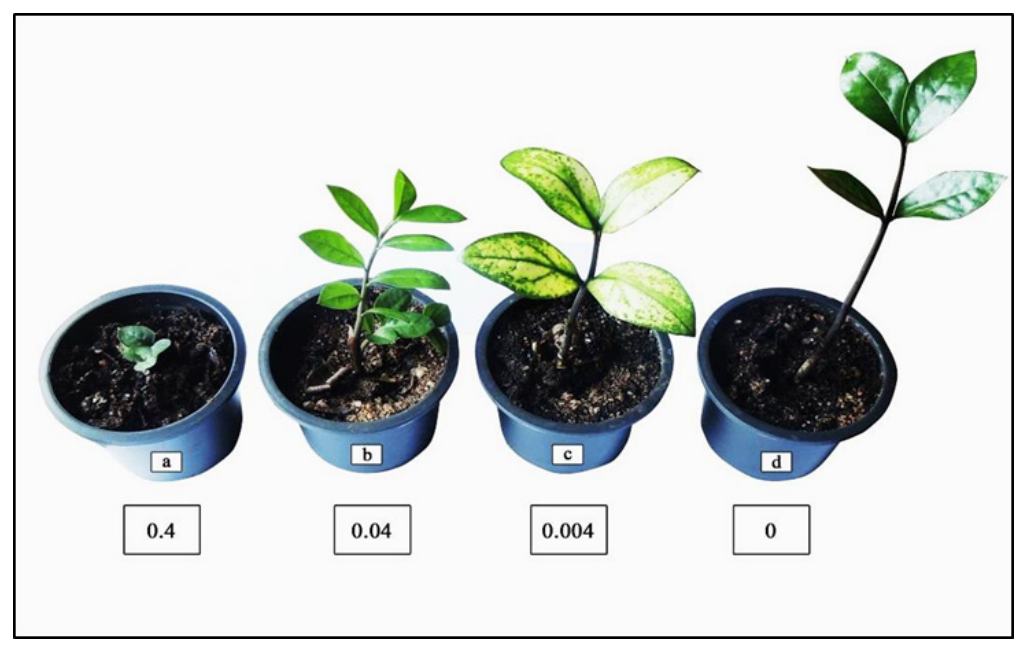

Figure 1: Outcomes after application of different concentrations of colchicine for 24 hours to Zamioculcas zamiifolia leaflets with callus, and growing them for six months in a $70 \%$ shaded greenhouse. a) $0.4 \%$, b) $0.04 \%$, c) $0.004 \%$ and d) $0 \%$ (distilled water control, original plant).

\section{CONCLUSION}

Attractive variants of Z. zamiifolia viz. dwarf plants and plants with variegated leaflets were produced within one year using colchicine treatments in the present study. Availability of only one species under this genus restricts the use of conventional breeding methods to generate new variants of this plant. Modern breeding techniques like genetic engineering can also be applied, but they are costly and more importantly take a longer period to produce new variants. Chemical mutagenesis provides a relatively low cost and rapid way of generating new plants with attractive features to the floriculture industry.

\section{ACKNOWLEDGEMENTS}

We thank Mr. M.M.D.J. Senaratne, Deputy Director, Research and Development unit, and Dr. S. A., Krishnaraja, Director General, Department of the National Botanic Gardens, Peradeniya, Sri Lanka for guidance and partial financial support for the study.

\section{DECLARATION OF COLFLICT OF INTEREST}

Authors declare no conflict of interest.

\section{REFERENCES}

Aisyah, S.I. and Marwoto, B. (2001). Induced mutation of Chrysant (Dendranthema grandiflora Tzvelev) through plantlet irradiation. Proceedings of SEAG Symposium. Los Banos, the Philippines.

Breuer, C., Stacey, N.J., West, C.E., Zhao, Y., Chory, J., Tsukaya, H., Azumi, Y., Maxwel, I. A., Roberts, K. and Sugimoto-Shirasu, K. (2007). BIN4, a novel component of the plant DNA topoisomerase VI complex, is required for endo-reduplication in Arabidopsis. The Plant Cell 19(11): 3655-3668.

Burchett, M., Torpy, F. and Tarran, J. (2008). Interior plants for sustainable facility ecology and workplace productivity. Proceedings of Ideaction'08 - Enabling Sustainable Communities; 7-9 May 2008, Gold Coast, Queensland.

Datta, S.K. and da Silva. J.A.T. (2006). Role of induced mutagenesis for development of new flower colour and type in ornamentals. In: J.A.T. Da Silva (ed), Floriculture, Ornamentals and Plant Biotechnology: Advances and Topical Issues. Vol. 1. Global Science Books Ltd., Middlesex, Pp. 640-645.

Datta, S.K., Misra, P. and Mandal, A.K.A. (2005). In-vitro mutagenesis-a quick method for establishment of solid mutant in chrysanthemum. Current Science 88: 155158.

De, L.C. (2017). Improvement of ornamental plants-a review. International Journal of Horticulture 7: 180204.

Eng, W.H. and Ho, W.S. (2019). Polyploidization using colchicine in horticultural plants: A review. Scientia Horticulturae 246: 604-617.

$\mathrm{Gu}$, Y. (2015). Cut flower productivity and economic analysis, polyploidy induction in two Zinnia varieties, Zinnia pollination mechanisms and DNA content of Zinnia species. Master's Thesis, North Carolina State University, Raleigh, NC, USA.

Guieysse, B., Hort, C., Platel, V., Munoz, R., Ondarts, M. and Revah, S. (2008). Biological treatment of indoor air for VOC removal.Potential and challenges. Biotechnology Advances 26(5): 398-410.

Ibrahim, R., Ahmad, Z., Salleh, S., Hassan, A.A. and Ariffin, S. (2018). Mutation Breeding in Ornamentals, volume 11.Ornamental Crops, $1^{\text {st }}$ Edition, Springer. Cham.

Irga, P.J., Pettit, T.J. and Torpy, F.R. (2018). The phytoremediation of indoor air pollution: a review on the technology development from the potted plant through to functional green wall bio- filters. Reviews in Environmental Science and Bio-Technology 17(2): 395-415.

Jadrná, P., Plavcová, O. and Kobza, F. (2011). Morphological changes in colchicine--treated Pelargonium $\times$ hortorum LH Bailey greenhouse plants. Horticultural Science 37(1): 27-33.

Jambhulkar, S.J. (2002). An extreme dwarf mutant in sunflower. Current Science 83(2): 116-116.

Lehrer, J.M., Brand, M.H. and Lubell, J.D. (2008). Induction of tetraploidy in meristematically active 
seeds of Japanese barberry (Berberis thunbergii var. atropurpurea) through exposure to colchicine and oryzalin. Scientia Horticulturae 119(1): 67-71.

Liu, G., Li, Z. and Bao, M. (2007). Colchicine-induced chromosome doubling in Platanus acerifolia and its effect on plant morphology. Euphytica 157(1-2): 145154.

Ma, Y., Xue, H., Zhang, L., Zhang, F.,Ou, C., Wang, F. and Zhang, Z. (2016). Involvement of auxin and brassinosteroid in dwarfism of autotetraploid apple (Malus $\times$ domestica). Scientific Reports 6: 26719.

Manzoor, A., Ahmad, T., Bashir, M.A., Baig, M.M.Q., Quresh, A.A., Shah, M.K.N. and Hafiz, I.A. (2018). Induction and identification of colchicine induced polyploidy in Gladiolus grandiflorus 'White Prosperity'. Folia Horticulturae, 30(2): 307-319.

Mujib, A. (2005). Colchicine induced morphological variants in pineapple. Plant Tissue Culture and Biotechnology 15(2): 127-133.

Pirkoohi, M.H., Keyvanloo, M. and Hassanpur, M. (2011). Colchicine induced polyploidy in mint by seed treatment. The International Journal of Agriculture and Crop Sciences 3(4): 102-104.

SAS. (1999).SAS/STAT user's Guide, Version 8 (Vol. 2). SAS Institute, Cary, NC, USA.

Seneviratne, K.A.C.N. and Wijesundara, D.S.A. (2004). New African violets (Saintpaulia ionantha H. Wendl.) induced by colchicine. Current Science 87: 138-140.

Seneviratne, K.A.C.N., Daundasekera, W.A.M., Kulasooriya, S.A. and Wijesundara, D.S.A. (2013). Development of rapid propagation methods and a miniature plant for export-oriented foliage, Zamioculcas zamiifolia. Ceylon Journal of Science (Biological Sciences) 42(1): 55-62.

Sriprapat, W. and Thiravetyan, P. (2013). Phytoremediation of BTEX from indoor air by Zamioculcas zamiifolia. Water, Air, \& Soil Pollution 224(3): 1482.
Sriprapat, W., Boraphech, P. and Thiravetyan, P. (2014). Factors affecting xylene-contaminated air removal by the ornamental plant Zamioculcas zamiifolia. Environmental Science and Pollution Research 21(4): 2603-2610.

Tarran, J., Torpy, F. and Burchett, M. (2007). Use of living pot-plants to cleanse indoor air-research review. Proceedings Of 6th International Conference On Indoor Air Quality, Ventilation \& Energy Conservation, Sustainable Built Environment, Sendai, Japan, Oct., Vol III, Pp. 249-256.

Thongkham, L. and Phavaphutanon, L. (2018). Effect of position and size of leaflets on rooting and rhizome formation of ZZ plant (Zamioculcas zamiifolia (Lodd.) Engl.) leaflet cuttings. Agriculture and Natural Resources 52(3): 246-249.

Vanzie-Canton, S.D. and Leonhardt, K.W. (2007). In vivo polyploidization of Zamioculcas zamiifolia. Proceedings of VI International Symposium on New Floricultural Crops, June, 813: 531-538.

Wong, W. (2009). The Garden Plants of China. Green Culture Singapore. Available from www.gardeningwithwilson. com.

Xu, L., Najeeb, U., Naeem, M.S., Daud, M.K., Cao, J.S., Gong, H.J., Shen, W.Q. and Zhou, W.J. (2010). Induction of tetraploidy in Juncus effusus by colchicine. Biologia Plantarum 54(4): 659-663.

Zhang, Q., Zhang, F., Li, B., Zhang, L. and Shi, H. (2016). Production of tetraploid plants of Trollius chinensis Bunge induced by colchicine. Czech Journal of Genetics and Plant Breeding 52(1): 34-38. 